\title{
KERBAU UNTUK LELUHUR: DIMENSI HORIZONTAL DALAM RITUS KEMATIAN PADA AGAMA MERAPU
}

\section{Gunawan $^{\bowtie}$}

Jurusan Sosiologi dan Antropologi, Fakultas Ilmu Sosial, Universitas Negeri Semarang, Indonesia

\section{Info Artikel}

Sejarah Artikel:

Diterima Desember 2012

Disetujui Januari 2013

Dipublikasikan Maret 2013

\section{Keywords:}

sacred, profane;

buffalo sacrifice; marapu religion.

\begin{abstract}
Abstrak
Penelitian ini bertujuan menggali makna yang terkandung dalam ritual mengorbankan kerbau dalam ritus kematian pada agama Marapu. Pengamatan dilakukan pada masyarakat Sumba penganut agama merapu. Fenomena keagamaan dalam masyarakat secara antropologis dapat dilihat dari aras sakral dan profan. Aras sakral menempatkan fenomena keagamaan dalam hubungan vertikal antara manusia dengan tuhan sebagai pemilik kekuatan adikodrati. Sedangkan pada aras profan melihat fenomena keagamaan dalam hubungan horisontal yang terbangun dalam relasi sosial antar pendukungnya. Tulisan ini menunjukkan bahwa dalam kehidupan sehari-hari aras sakral dan profan tidaklah terpisah sama sekali. Aktifitas yang tampaknya profan ternyata terkait dengan wilayah sakral seperti yang terjadi pada masyarakat Sumba. Keberadaan ternak khususnya kerbau menjadi penghubung antara wilayah sakral dan profan. Memelihara ternak, khususnya kerbau merupakan aktifitas sehari-hari yang bersifat profan namun menjadi sakral manakala kerbau hadir dalam ritual kematian. Sehingga secara nyata aktifitas profan dalam memelihara ternak khususnya kerbau akan menjamin tetap tegaknya agama Marapu.
\end{abstract}

\begin{abstract}
The objective of this study is to reveal the meaning behind the sacrifice of buffalo in the death rituals of Merapu religion. The observation was done among Sumba community, the followers of Merapu religion. Religious phenomena in the anthropological community can be seen from the sacred and profane dimension. In sacred level, religious phenomenon builds the vertical relationship between man and God as the owner of supernatural power. While the level of profane views religious phenomena in a horizontal relationship built within particular social relations. This paper shows that in the level of everyday life, the sacred and the profane are not separated at all as best exemplified by Sumba community ritual of buffalo sacrifice. Seemingly profane activities were related to the sacred as exemplified by Sumba people particularly the followers of Merapu belief. The presence of livestock especially buffaloes became a liaison between the sacred and the profane. Livestock, particularly buffalo are daily profane activities, but when the buffalo are present in the death ritual, they become sacred. Profane activities in raising livestock especially the buffalo ensures the upholding of Marapu belief.
\end{abstract}

(C) 2013 Universitas Negeri Semarang

Alamat korespondensi:

Gedung C7 Lantai 1 FIS UNNES

ISSN 2086-5465

Kampus Sekaran, Gunungpati, Semarang, 50229

E-mail: gunawan@gmail.com 


\section{PENDAHULUAN}

Ekspresi keagamaan yang dipraktekkan oleh manusia tidaklah muncul begitu saja tanpa alasan. Ekspresi keagamaan merupakan bentuk empiris dari pemikiran terhadap hal-hal yang dirasakan manusia sebagai gejala yang tidak dapat dijelaskan melalui logika dan akal. Pengalaman-pengalaman ghaib dan magis dirasakan manusia melalui melalui berbagai peristiwa seperti mimpi, lahir, dan mati, atau juga melalui fenomenafenomena alam seperti bencana gunung meletus, gempa buki atau obyek material yang dianggap luar biasa seperti gunung, laut, angin, bulan, dan matahari. Lewat obyekobyek material seperti itulah manusia mengimajinasikan adanya satu kekuatan adikodrati yang mengatur dan menggerakkan segala fenomena yang terjadi di bumi.

Di banyak tempat, fenomena tentang peristiwa kelahiran dan kematian yang dialami manusia merupakan aspek yang paling penting dalam membangun sentimen religius manusia dari berbagai jaman (Banks, 2011; Damsholt, 2009; Dennis, 2012; Dane1y, 2011; Gray, 2009; Hardenberg, 2010; Mitchell, 2009; Roemer, 2012; Okawaro, 2010; Quack dan Tobelman, 2010; Strathern dan Stewart, 2010, 2012; Sayers, 2012; Schafer, 2011; Smith, 2010; Samuel, 2010; Traphagan, 2012). Data arkeologis menunjukkan bahwa sejak masa paleolitikum manusia sudah mengenal adanya perlakuan khusus terhadap orang yang meninggal, misalnya dengan menyertakan barang-barang yang dimiliki pada masa hidupnya ke dalam kubur. Dalam banyak religi menganggap kematianseseorang bukanlah akhir dari kehidupan manusia tetapi hanya bentuk kehidupan saja yang berpindah ke suatu tempat.

Praktek pemujaan terhadap kekuatan adikodrati dilakukan manusia sebagai upaya untuk menjaga keteraturan dan keseimbangan terhadap apa yang terjadi dalam kehidupan manusia. Pada masyarakat yang meyakini bahwa gunung meletus adalah bentuk kemarahan dari "penguasa gunung" maka praktek pemujaan terhadap "penguasa gunung" merupakan upaya untuk menjaga agar tidak menimbulkan kemarahan yang dapat mengakibatkan gunung meletus. Atau ritual-ritual yang dilakukan masyarakat nelayan terhadap pengendali kekuatan laut adalah upaya untuk menghindari terjadinya bencana akibat kemarahan "sang penguasa laut".

Gagasan mengenai keberadaan dewadewa penguasa laut dan angin pada masa Yunani, ataupun pada masyarakat India merupakan konsepsi manusia mengenai alam supranatural. Namun sebelum kepercayaan tersebut berkembang, sudah dikenal adanya sistem religi yang dikenal dengan istilah animisme, yaitu konsepsi manusia religius yang membubuhkan adanya "jiwa" dalam makhluk hidup maupun benda mati dan tempat-tempat tertentu. Jiwa-jiwa adikodrati tersebut juga memiliki sifat seperti manusia yang hidup sehingga masih membutuhkan makan, minum, dan bisa juga marah. Sehingga manusia juga menyediakan apa yang dibutuhkan jiwa-jiwa adikodrati misalnya dengan memberi sesaji atau tumbal untuk menjaga agar tidak menyebabkan kemarahan yang akan membawa malapetaka bagi manusia.

Praktek-praktek religius yang dilakukan manusia memiliki implikasi sosial dalam hubungan antar individu di dalam masyarakat (Cohen, 2009; Fischer, 2008; Huang, 2008). Oleh karenanya agama kemudian menjadi salah satu bagian penting dalam kajian mengenai masyarakat. Durkheim merupakan salah satu sosiolog terkemuka yang melihat agama sebagai fenomena sosial yang dijelaskan dengan adanya solidaritas sosial dan integrasi dalam masyarakat. Fokus perhatian Durkheim adalah tentang totemisme di kalangan masyarakat primitif. Pada masyarakat primitif kelompok sosial dibentuk berdasarkan klan-klan yang di dalamnya memiliki ikatan primordial yang kuat terhadap klannya. Dalam praktek keagamaan di kalangan masyarakat primitif dikenal simbolisasi atas sesuatu yang dianggap sakral/suci. Simbol ini berupa totem yang digunakan untuk mengidentifikasikan anggota kelompoknya dalam satu klan. Totem-totem ini adalah representasi dari kekuatan supranatural yang diyakini memiliki hubungan suci dengan suatu klan. Dengan demikian sesunguhnya 
klan itu juga memiliki kekuasaan tentang sakral. Emosi yang tercipta atas dasar pemujaan terhadap kekuatan supranatural yang direpresentasikan melalui totem merupakan bukti yang diajukan Durkheim bahwa fenomena agama merupakan fenomena sosial yang secara langsung membangkitkan solidaritas dan interaksi di dalam masyarakat.

Pandangan Durkheim ini banyak dikritik, gejala totemisme bukanlah gejala universal terhadap munculnya fenomena agama, selain itu totemisme lebih sebagai fenomena sosial daripada fenomena religius (Dhavamony 95:76). Tetapi setidaknya apa yang dilakukan Durkhiem merupakan bagian penting yang menunjukkan bahwa fenomena agama bukanlah semata-mata fenomena menganai hubungan manusia secara vertikal dengan suatu kekuatan adikodrati dan alam transenden tetapi juga memiliki implikasi terhadap hubungan horisontal antara manusia di alam mondial. Tulisan ini merupakan upaya untuk melihat bagaimana demensi horisontal yang terjadi dalam ritual kematian pada masyarakat Sumba yang memiliki sistem religi lokal yang dikenal dengan sebutan Marapu.

\section{METODE PENELITIAN}

Penelitian dilakukan dilakukan di Sumba secara etnografis selama enam bulan di tahun 2010. Amatan saya fokus pada fungsi ritual penyembelihan kerbau dan maknanya secara social dan secara religious bagi masyarakat Marapu. Saya anggap penting masalah ini untuk membuktikan secara empirik tesis tentang keterkaitan antara yang religious dan yang profane dalam kehidupan sehari-hari.

\section{HASIL DAN PEMBAHASAN}

Fenomena agama, memiliki demensi vertikal dan horizontal, demensi vertikal merupakan ekpresi dari hubungan antara manusia dengan tuhan/adikodrati sedangkan demensi horisontal merupakan efek dari praktek religius terhadap hubungan antar manusia. Kajian antropologis mengenai agama lebih banyak menitik beratkan pada demensi horisontal dari fenomena agama, yaitu dengan melakukan kajian untuk melihat apa dan bagaimana agama berfungsi di dalam masyarakat.

Dalam kaitanya dengan sistem religi, Sumba merupakan salah satu daerah di Indonesia yang menarik untuk dilihat lebih lanjut. Di tengah perkembangan agama-agama monoteis yang semakin kuat dewasa ini, rupanya sistem religi masyarakat lokal yang dikenal dengan istilah marapu masih dipraktekkan hingga hari ini. Ekspresi religius ini tercermin dalam berbagai hal misalnya bentuk kampung dan pemukiman, serta ritualritual keagamaan yang masih dipraktaktekkan. Sebelum melihat lebih jauh mengenai praktek-praktek sistem religi marapu, terlebih dahulu akan dipaparkan mengenai apa yang dimaksud dengan marapu. Marapu adalah istilah orang sumba untuk menyebut roh leluhur yang sudah meninggal. Dalam sistem religi orang Sumba roh orang yang sudah meninggal/leluhur masih senantiasa memiliki hubungan dan mempengaruhi hidup manusia. Roh tersebut bersemayam dalam berbagai tempat misalnya di hutan, ladang, kampung dan rumah. Tempat-tempat bersemayamnya marapu biasanya akan diberi tanda misalnya dengan tumpukan batu. Tanda berupa beberapa batu yang ditumpuk disebut dengan katoda. Katoda dapat dijumpai di ladang, kebun, dan dalam perkampungan, bahkan di dalam rumah. Di dalam rumah katoda diletakkan di bagian atas langit-langit rumah sekaligus sebagai loteng utuk menyimpan benda-benda berharga. Marapu bukanlah tuhan, melainkan arwah leluhur yang memiliki peran sebagai mediator yang menghubungkan manusia dengan tuhan. Karena memiliki peran sebagai mediator, maka arwah nenek moyang memiliki nilai religius yang sangat penting bagi orang Sumba. Arwah marapu inilah yang akan menyampaikan doa-doa dan permohonan manusia agar disampaikan kepada tuhan.

Penghormatan terhadap roh leluhur ini dimulai ketika ada orang yang meninggal. Acara penguburan merupakan acara yang syarat dengan makna religius dan sosial. Adanya kematian dalam suatu keluarga ditandai dengan dipukulnya gamelan berupa 
empat gong kecil dan satu gendang kecil. Gamelan akan dibunyikan sepanjang waktu oleh para pemuda secara bergantian hingga acara penguburan berakhir. Dalam tradisi orang Sumba acara kematian dapat berlangsung hingga berhari-hari. Orang yang meninggal tidak langsung dimakamkan tetapi masih disemayamkan di dalam rumah hingga hari penguburan dilaksanakan. Saat ada kematian para warga dan keluarga akan segera berkumpul di rumah duka. Mayat akan di mandikan dengan air kelapa kemudian dibungkus dengan kain tenun hingga menutup semua bagian tubuhnya. Jenasah diletakkan dalam posisi duduk di atas kursi dari bambu yang sekaligus berfungsi sebagai tandu untuk mengangkat jenasah ke tempat pemakaman. Jenasah diletakkan di bagian dalam rumah, dekat pintu masuk. Sekelompok pemuda berkumpul dibalai-balai depan rumah sambil menabuh gamelan secara bergantian.

Selama suasana berkabung orangorang akan berdatangan dengan membawa kain tenun, hewan ternak seperti babi, anjing atau kerbau. Setiap malam keluarga dan tetangga berdatangan untuk mete, yaitu datang ke rumah duka untuk menyatakan rasa belasungkawa. Kain tenun yang dibawa para tamu akan diselimutkan ke badan jenasah, Sedangkan hewan yang dibawa akan disembelih untuk memberikan jamuan kepadatamu-tamu yang datang. Acara mete berlangsung beberapa hari bahkan hingga satu minggu, tergantung dari situasinya. Acara penguburan baru dilakukan setelah proses penyiapan batu kubur selesai atau setelah seluruh keluarga yang meninggal-terutama anak-sudah datang. Tetapi apa bila ada salah satu keluarga belum datang, maka akan ditunggu sampai kedatangannya, kecuali jika sudah ada kepastian bahwa tidak bisa datang.

Selama jenasah belum dimakamkan, keluarga selalu menjaga di samping jenasah. Jenasah akan dilayani sebagaimana layaknya ketika masih hidup dengan menyediakan sirih pinang dan makanan. Hal itu dilakukan sebagai bentuk penghormatan pada roh marapu agar tidak marah, karena bila tidak disediakan makanan dan dilayani secara baik akan mengakibatkkan kemarahan dan berakibat fatal bagi keluarga yang masih hidup. Konon sifat baik buruknya seseorang ketika masih hidup akan menentukan kondisi jenasah. Orang yang semasa hidupnya banyak berbuat baik, maka jenasahnya tidak akan mengeluarkan bau walaupun tidak dikuburkan hingga berberapa hari, tetapi akan terjadi sebaliknya jika semasa hidupnya banyak berbuat jahat.

Berlangsungnya acara kematian ini dapat menjadi ukuran tentang status sosial dan seberapa penting keluarga orang yang meninggal ini di dalam masyarakat. Masyarakat Sumba mengenal adanya 3 pelapisan sosial yaitu kaum bangsawan (marabba) orang merdeka (kabihu), dan hamba (ata). Ketiga lapisan ini menentukan seberapa besar upacara yang akan berlangsung. Pada keluarga yang mengalami kedukaan, seluruh keluarga akan berkumpul untuk membicarakan seberapa banyak hewan yang akan dikorbankan. Dalam pembicaraan ini seringkali terjadi persaingan gengsi di antara anggota keluarga terutama oleh para menantu laki-laki. Seorang menantu laki-laki harus datang membawa seekor kerbau jika ada keluarga istrinya yang meninggal. Para menantu tersebut akan bersaing untuk memberikan hewan korban yang lebih banyak dan lebih besar disbanding yang lain. Sebuah tindakan yang memalukan dan aib apabila tidak mampu membawa hewan ternak dalam acara penguburan itu. Kerbau yang dibawa saat acara penguburan akan disembelih pada saat pemakaman dan dipercaya sebagai hewan yang akan digunakan sebagai kendaraan roh orang yang meninggal. Hewan lain yang berupa babi, anjing adalah hewan kecil hanya digunakan untuk menjamu orang-orang yang datang saat mete.

Pada acara kematian hewan yang dipotong untuk menjamu tamu bisa mencapai puluhan. Terlebih lagi jika yang meninggal adalah kaum bangsawan. Setiap orang yang datang akan dijamu dengan makanan ringan, minum, dan makan dengan daging dari hewan yang diembelih. Semakin lama acara mete, semakin banyak orang yang datang dan semakin banyak pula bahan makanan dan hewan yang harus disediakan. Jumlah babi dan kerbau yang disembelih akan memberikan status tertentu bagi seseorang. Semakin 
banyak hewan yang disembelih, semakin meningkatkan gengsi seseorang. Besar kecilnya ukuran hewan juga menentukan gengsi seseorang. Besarnya kerbau yang dipotong diukur dengan panjang tanduknya, semakin panjang ukuran tanduknya akan meningkatkan gengsi seseorang. Sedangkan besar kecilnya babi diukur dari jumlah orang yang kuat untuk memikulnya, semakin banyak orang yang dibutuhkan untuk memikul babi, maka semakin besar ukuran babi dan semakin besarjuga nilai gengsi orang yang memberikannya.

Tanduk kerbau dan rahang babi yang sudah disembelih akan digantungkan di depan pintu masuk atau di teras rumah. Sehingga dengan melihat panjangnya tanduk serta jumlah rahang yang digantungkan akan menunjukkan status sesorang. Semakin panjang tanduk kerbau yang dipasang, semakin banyak rahang babi yang digantungkan maka akan semakin tinggi status seseorang.
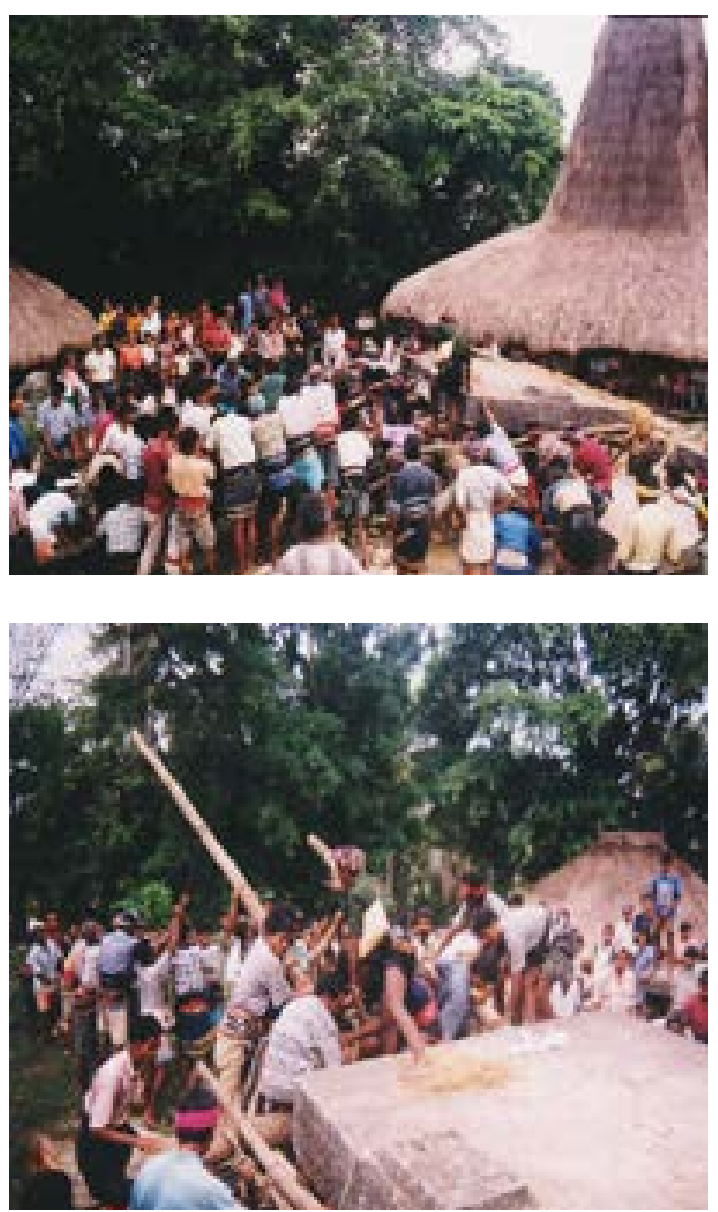

Gambar 1. Memasukkan Jenasah ke dalam peti kubur batu
Setelah seluruh keluarga berkumpul dan hari pemakaman sudah ditentukan. Jenasah dibawa ke ke desa induk (paraingu) yaitu desa yang dianggap sebagai asal usul nenek moyang. Jenasah dipikul dengan tandu sambil diiringi irama gong yang ditabuh sepanjang perjalanan. Sanak famili dan tetangga ikut dalam iring-iringan rombongan, termasuk juga kerbau dan babi yang akan dikorbankan. Hewan-hewan dihias dengan daun-daunan dan janur kuning. Lokasi pemakaman terletak di tangah-tengah lokasi pemukiman. Janasah akan dimasukkan ke dalam peti kubur yang berupa batu kemudian akan ditutup kambali. Peti kubur batu akan digunakan untuk memakamkan beberapa mayat. Dalam satu peti kubur dapat digunakan untuk memakamkan jenasah yang memiliki hubungan kerabat dengan jarak 1 generasi yaitu antara nenek/kakek dengan cucunya. Aturan peletakkan ini dimaksudkan agar roh cucu dapat melayani roh kakek/neneknya. Seorang anak tidak boleh dimakamkan dalam satu peti kubur yang sama dengan orang tuanya karena biasanya hubungan anak dengan orang tua bisa mengalami situasi yang tidak harmonis. orang akan merasa lebih sayang dengan cucu dari pada anaknya, seorang cucu juga akan lebih menghormati kakak/neneknya daripada orangtuanya.

Setelah jenasah dimasukkan ke dalam peti kubur, kerbau yang akan dikorbankan dibawa mendekat ke tempat pemakaman. Cara penyembelihan kerbau dilakukan dengan cara mengayunkan parang ke leher kerbau. Pada saat pemotongan kerbau merupakan saaat yang penting bagi orang yang memotongnya. Orang dapat menunjukkan ketajaman parang yang dimiliki dan ketrampilannya dalam menebas leher kerbau. Apabila dalam satu kali tebas saluran darah dan urat nadi dan nafas kerbau putus maka orang yang memotongnya akan disegani orang tetapi apabila tidak bisa melakukannya, maka akan menjadi olok-olok banyak orang.

Setelah kerbau terjungkal kehabisan darah, beramai-ramai dikuliti kemudian dagingnya akan dipotong-potong lalu dibagikan kepada semua orang yang berada di tempat itu. 


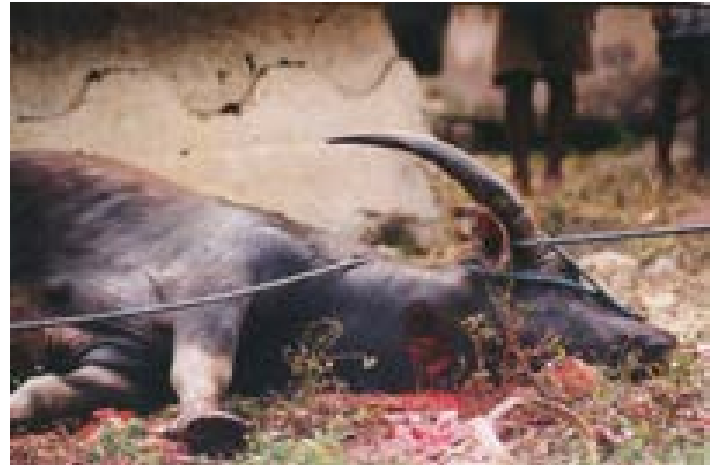

Gambar 2. Kerbau persembahan untuk Merapu
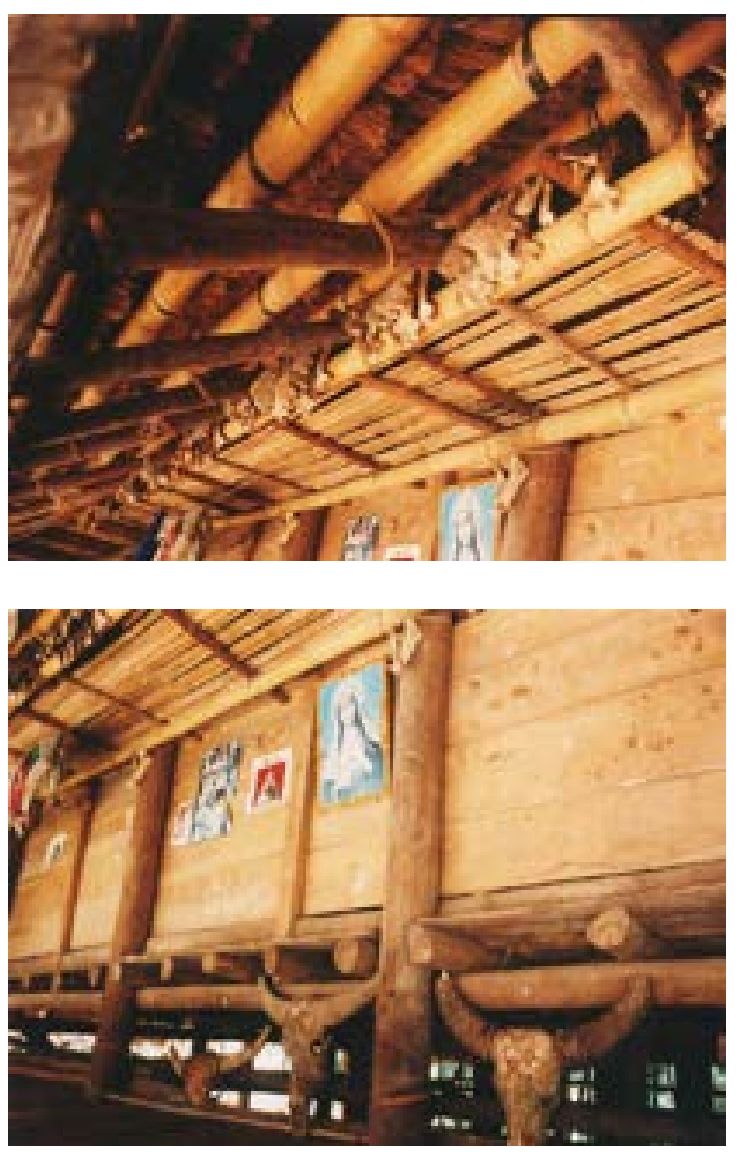

Gambar 3. Rahang babi dan kepala kerbau, diletakkan didepan rumah untuk menunjukan

\section{SIMPULAN}

Dalam kajian antropologi mengenai agama mengenal dua dikotomi penting yaitu sakral dan profan. Sakral merupakan konsep religius mengenai hal-hal yang memiliki nilai suci dan berkaitan dengan pelarangan dan berhubungan dengan alam transenden, sedangkan profan adalah praktek sehari-hari terutama yang berhubungan dengan alam mondial. Bagi Orang Sumba, binatang ternak khususnya babi dan kerbau memiliki nilai sakral dan profan. Nilai sakral melekat pada hewan ternak ketika hewan tersebut digunakan debagai hewan persembhan dalam ritual keagamaan. Sedangkan hewan dalam arti profan yaitu ketika dalam hidup seharihari. Pembagian antara profan dan sakral bukanlah dua wilayah yang sama sekali tidak bersentuhan. Pada kenyataannya antara sakral dan profan ini berhubungan satu sama lain dalam kehidupan sehari-hari orang Sumba. Dunia sakral dan profan dihubungkan dengan keberadaan hewan ternak yang dipelihara oleh orang sumba.
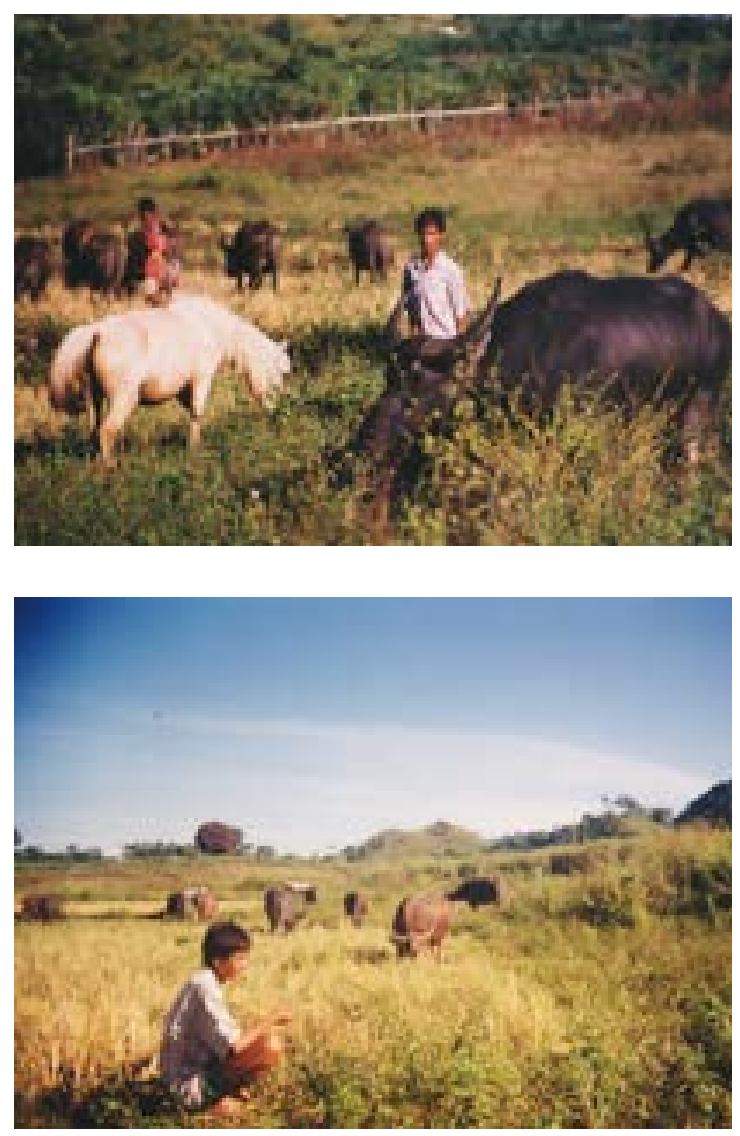

Gambar 4. Menggembala ternak: Aktivitas profan yang terkait dengan wilayah sakral

Dalam aras profan keberadaan hewan ternak merupakan bentuk adaptasi terhadap kondisi ekologisnya. Kondisi alam wilayah Sumba memiliki curah hujan rendah dan kondisi alam yang cenderung kering Lahan pertanian berupa ladang dengan hamparan 
padang yang luas. Dalam kondisi geografis sedemikian rupa keberadaan padang savana memungkinkan untuk melakukan penggembalaan ternak. Pemeliharaan hewan ternak merupakan bentuk adaptasi ekonomi sebagai moda produksi pangan mereka. Setiap keluarga memiliki ternak berupa babi dan kerbau dan dirawat oleh anggota keluarga bersamasama. Dalam satu keluarga membuat jadual penggembalan ternak untuk menentukan siapa yang menggembalakan ternak secara bergantian. Selain itu ternak-ternak ini juga memiliki nilai ekonomis karena dapat juga diperjulan belikan dalam situasi tertentu, misalnya untuk biaya pengobatan keluarga yang sakit, atau memperbaiki rumah. Tetapi pada saat ada sanak saudara yang meninggal, kerbau atau babi menjadi hewan persembahan untuk penghormatan kepada leluhur sekaligus penyelamat gengsi mereka karena bisa menunjukkan kemampuannya mengorbankan hewan. Dengan demikian dapat dikatakan bahwa melalui pengorbanan hewan itulah sistem sosial masyarakat diintegrasikan ke dalam simbol-simbol religius. Pertanyaan yang harus dijawab selanjutnya adalah: ketika agama berkembang dan orang Sumba mulai beralih menganut sistem religi monoteis dengan menganut agama-agama besar khususnya Kristen dan Katholik, masihkan sistem religi marapu mampu mengintegrasikan sistem sosial mereka?

\section{DAFTAR PUSTAKA}

Adams, R. 2004. The Megalithic Tradition of West Sum$b a$. Fraser: Simon Fraser University.

Aris, L.O. 2012. Fungsi Ritual Kaago-ago pada Masyarakat Muda di Sulawesi Tenggara. Jurnal Komunitas.4(1):18-16

Banks, W.D. 2011. On the Stabilizing Power of Priests: Action and Meaning in the Possession Rituals of Priests in Southern Ghana. Journal of Ritual Studies. 25 (1): 45-53.

Cohen, E.B. 2009. Opening and Closing Ritual in Aikid and Karate and the Dismantling of Violence. Journal of Ritual Studies. 23 (1): 29-44.

Danely, J.A. 2011. Repetition and the Symbolic in Contemporary Japanese Ancestor Memorial Ritual. Journal of Ritual Studies. 26 (1): 19-32.

Damsholt, T. 2009. Ritualizing and Materializing Citizenship. Journal of Ritual Studies. 23 (2): 17-29.

Dhavamony, M. 1995, Fenomenologi Agama. Yogyakarta: Kanisius.
Dennis, G.W. 2012. Purity and Transformation: The Mimetic Performance of Scriptural Texts in the Ritual of Taharah. Journal of Ritual Studies. 26 (1):51-64.

Fox, J. 1990. The Flow of Life: Essays on Eastern Indonesia. Harvard: Harvard University Press.

Fischer, J. 2008. Nationalizing Rituals? The Ritual Economy in Malaysia. Journal of Ritual Studies 22 (2): 13-22.

Gunawan, I. 2000. Herarchy and Balance a Study of Wanokaka Social Organization.

Canberra: a Publication of the Depertment of Anthropology and Research School of Pacific Asian Studies The Australian National University.

Gray, J. 2009. Marriage Ritual in Nepal: Space, Performance and Tacit Knowledge. Journal of Ritual Studies. 23 (1): 45-60.

Huang, I.S. 2008. Coin and Healing Ritual Among the Amis in Taiwan: State, Images of Others, and Socio-Cosmic Order in Early 1930s. Journal of Ritual Studies 22 (2): 23-35.

Hardenberg, R. 2010. How to Overcome Death? - The Efficacy of Funeral Rituals in Kyrgyzstan. Journal of Ritual Studies. 24 (1): 29-43.

Janowitz, N. 2011. Inventing the Scapegoat: Theories of Sacrifice and Ritual. Journal of Ritual Studies. 25 (1):15-24.

Mitchell, J.P. 2009. Ritual Transformation and the Existential Grounds of Selfhood. Journal of Ritual Studies. 23 (2): 53-66.

Ostergaard K. 2009. The Process of Becoming Muslim: Ritualization and Embodiment, Journal of Ritual Studies. 23 (1): 1-13.

Okwaro, F. 2010. Modernity and Efficacy in Kenyan Ritual Healing. Journal of Ritual Studies. 24 (2): 57-79.

Quack, J. dan Sax, W.S. 2010. Introduction: The Efficacy of Rituals. Journal of Ritual Studies. 24 (1): 5-12.

Quack, J. dan Tobelman, P. 2010. Questioning "Ritual Efficacy”. Journal of Ritual Studies. 24 (1): 1328.

Roemer, M.K. 2012. Thinking of Ancestors (and Others) at Japanese Household Altars. Journal of Ritual Studies. 26 (1): 33-45.

Renard, B. 1988. Li'I marapau: Speech and ritual Among the Wewewa of West Sumba dalam Fox, James. (ed) To Speak in Pair, Essays on the Ritual Languages of Eastern Indonesia, Cambridge: Cambridge University Press.

Strathern, A. dan Stewart, P.J. 2009. Sorcery and Sister Exchange: Comparative Comments, Journal of Ritual Studies. 23 (1): 61-63.

Strathern, A. dan Stewart, P.J. 2009. Transforming Persons, Transforming Places, Journal of Ritual Studies. 23 (2): 1-3)

Strathern, A. and Stewart, P.J. 2010. Functions, Effects, and Efficacy: A Moving Walkway of Analyses. Journal of Ritual Studies. 24 (1): 1-4.

Strathern, A. dan Stewart, P. 2012. Thinking about Rituals, Thinking of the Ancestors. Journal of Ritual Studies. 26 (1): 47-49) 


\section{Gunawan / Komunitas 5 (1) (2013) : 93-100}

Samuel, G. 2010. Healing, Efficacy and the Spirits. Journal of Ritual Studies. 24 (2): 7-20.

Smith, F.M. 2010. Possession, Embodiment, and Ritual in Mental Health Care in India. Journal of Ritual Studies. 24 (2): 21-35)

Schafer, C. 2011. Celebrant Ceremonies: Life-centered Funerals in Aotearoa/New Zealand. Journal of Ritual Studies. 25 (1): 1-13.

Sharaby, R. 2011. Dual Liminality: Marriage Rituals of the Mountain Jews in a Changing Social Context. Journal of Ritual Studies. 25 (1): 25-44.

Sayers, W.R. 2012. Claiming Modes of Mediation in Ancient Hindu and Buddhist Ancestor Worship. Journal of Ritual Studies. 26 (1): 5-18.

Tremmel, W.C. 1976. Religion What Is It. Florida: University of South Florida.

Traphagan, J.W. 2012. Innovation and Ancestor Rituals. Journal of Ritual Studies. 26 (1): 1-3. 